\title{
Anti-predator response of Haliotis tuberculata is modified after only one generation of domestication
}

\author{
Sabine Roussel ${ }^{1, *}$, Thomas Bisch ${ }^{1,2}$, Sébastien Lachambre ${ }^{1,3}$, Pierre Boudry ${ }^{4}$, \\ Jean-Lou Gervois ${ }^{3}$, Christophe Lambert ${ }^{1}$, Sylvain Huchette ${ }^{3}$, Rob Day ${ }^{5}$ \\ ${ }^{1}$ Univ Brest, CNRS, IRD, Ifremer, LEMAR, 29280 Plouzané, France \\ ${ }^{2}$ AgroParisTech, 16 rue Claude Bernard, 75231 Paris Cedex 05, France \\ ${ }^{3}$ France Haliotis, 29880 Plouguerneau, France \\ ${ }^{4}$ Ifremer, Univ Brest, CNRS, IRD, LEMAR, 29280 Plouzané, France \\ ${ }^{5}$ School of Biosciences, University of Melbourne, Parkville, Victoria 3010, Australia
}

\begin{abstract}
Domestication of Haliotis tuberculata has only recently begun. During the process, we expect that behavioural and physiological traits may evolve to become more adapted to their captive environment. These modifications may result from intentional selection of production traits or unconscious and unintentional selection due to conditions experienced in the farm environment. To study this process at the earliest stage, the progeny of 3 different broodstocks obtained from wild parents, selected farmed abalone and randomly sampled farmed abalone, were studied. After rearing for 16 mo in separate tanks, offspring from the 3 progenies were placed together in sea cages at the same density. After 3 yr, behavioural traits were studied, and the immune status after a stress situation was assessed. Mortality and growth were also recorded. In spite of the fact that no significant differences were observed in survival, growth or immune status traits between the 3 progenies, less progeny from the selected broodstock performed the complete sequence of anti-predation behaviour, and they took more time to reach their hides compared to the wild progeny. In addition, the shell colours of the selected progeny were more orange and had more stripes compared to the brown-green colour of the wild progeny. Progeny of randomly sampled broodstock showed intermediate responses between those of wild and selected progeny. Our results suggest that associated behavioural trade-offs can take place after only one generation of selection to improve growth. This should be taken into consideration when using selected stocks for ranching or population enhancement programs.
\end{abstract}

KEY WORDS: Predation $\cdot$ Hiding behaviour $\cdot$ Haliotis tuberculata $\cdot$ Domestication $\cdot$ Selection Captive $\cdot$ Abalone

\section{INTRODUCTION}

Aquaculture is now being applied to many marine species, and thus these species are being modified in the process of domestication, both intentionally and unintentionally. It is unclear how fast this process may be, but because most marine animals are broadcast spawners and produce very large numbers of

\footnotetext{
${ }^{*}$ Corresponding author: sabine.roussel@univ-brest.fr
}

eggs, there is a great potential for rapid selection in such species. If animals from aquaculture are to be used for sea-ranching or to boost declining wild stocks, it is important to understand the modifications that may arise during the early stages of domestication.

Abalone are marine gastropods found on most of the continents, with more than 56 species described worldwide (Geiger 2000). These gastropods inhabit

() The authors 2019. Open Access under Creative Commons by Attribution Licence. Use, distribution and reproduction are unrestricted. Authors and original publication must be credited. 
rocky habitats (Poore 1972, Shepherd 1973, Clavier \& Chardy 1989). They live on rocks or coral, in narrow crevices or under boulders. Abalone show strong photonegative behaviour, with movement and feeding mainly observed during the night (Momma \& Sato 1969). This pronounced behavioural rhythm has been interpreted as an efficient way to avoid predators (Shepherd 1973). Indeed, abalone have numerous predators such as sea otters (Hines \& Pearse 1982), crabs, stingrays, fish (Shepherd 1973, Griffiths \& Gosselin 2008) and starfish (Cox 1962, Day et al. 1995). Day et al. (1995) described escape responses exhibited by Haliotis rubra when attacked by starfish: extension of their tentacles to detect the predator is followed by retraction of the tentacles when contact is made with the starfish tube feet, then lifting of its shell followed by violent twists of the shell from one side to the other to break the starfish's grip, almost always followed by a 'running' response. In addition, abalone often eject mucus, which probably helps to mask the direction of escape and might have repellent proprieties (Day et al. 1995, Bancalà 2009).

Price (1984, p. 3) defined animal domestication as 'that process by which a population of animals becomes adapted to man and to the captive environment by some combination of genetic changes occurring over generations and environmentally induced developmental events reoccurring during each generation'. In fish, Teletchea \& Fontaine (2014) defined it as the consistent control of reproduction over successive generations, involving maintaining and breeding fish in captivity, with broodstock management and rearing of the larvae and juveniles. Domesticated terrestrial animals are often characterized by a change in quantitative rather than qualitative behavioural responses (Price 1999); for example, domesticated animals show reduced sensitivity to changes in their environment, even if fear responses are still observed. The same process is described in marine animals (Huntingford \& Adams 2005). Indeed, a shift is observed from resource conservation, foraging and predator avoidance functions (Thorpe 2004) toward resource allocation to growth and reproduction. Even though studies are rare, domestication has been shown to reduce physiological responses to stressors in domesticated mammals such as guinea pigs in comparison to wild cavy (Kunzl \& Sachser 1999) and to improve chronic stress resistance as well as the immune status of Eurasian perch after 4 generations of reproduction in captivity (Douxfils et al. 2011). In molluscs, behavioural and physiological consequences are far less known, prob- ably due to the limited behavioural repertoire of bivalves, the major cultivated species.

As for many species of abalone cultured around the world (Robinson et al. 2010, Rhode et al. 2012), domestication of the European species H. tuberculata started only recently. However, the effect of domestication on behaviour has rarely been studied (Robinson et al. 2013). A first series of experiments on this species showed that wild abalone spent about twice as much time moving during the day, took longer to right themselves after being turned upside down (Lachambre et al. 2017b) and responded more to touching the foot (Lachambre et al. 2017a) compared to farmed abalone. However, because wild and farmed abalone were not raised in the same conditions, it was not possible differentiate developmental from genetic effects.

It is also important to study the unintended effects of selection for growth on other parameters. A negative change of untargeted traits in response to selection is described as a trade-off (Rauw et al. 1998).

Even if the relative contribution of genetic changes to the domestication process is often difficult to assess, comparing individuals from different origins subject to a common environment can provide clues about the effect of genetic-based differentiation (Conover 1998). Our experiment aimed to reveal the potential consequences of the first stages of domestication. Diurnal rhythm and responses to several challenging situations, such as predation and being turned upside down, were studied in offspring of 3 different origins, corresponding to 3 different levels of domestication (Teletchea \& Fontaine 2014): offspring from wild broodstock (entire life in captivity, with wild parents), offspring from randomly sampled farmed broodstock (entire life in captivity, with cultured parents but no selective breeding program) and offspring from selected farmed broodstock (entire life in captivity, with cultured parents from a selective breeding program focusing on specific goals). These 3 progenies were raised in a similar environment and studied at $3 \mathrm{yr}$ of age. This experiment allowed the evaluation of any trade-offs associated with unintentional selection due to farm conditions and due to selection for weight, the most frequent selection criterion used on farmed abalone. Because ranching programs and stock enhancement programs often use juveniles from farms, and possibly use broodstock that have been subject to selection, it is important to estimate the behavioural consequences of early stages of domestication on the behaviour of offspring and to consider the offspring's chance of survival in the wild. 


\section{MATERIALS AND METHODS}

\subsection{Animals and rearing procedure}

Abalone Haliotis tuberculata of 3 different origins were obtained for the study: wild abalone, randomly sampled farmed abalone and farmed abalone selected to improve growth (the heaviest $5 \%$ of the individuals from a cage containing 600 abalone). Farmed abalone broodstock were sampled from the France Haliotis stock $\left(48^{\circ} 36^{\prime} 46^{\prime \prime} \mathrm{N}, 4^{\circ} 33^{\prime} 30^{\prime \prime} \mathrm{W}\right.$; Plouguerneau, France). The farm broodstock were all the same age and the $3^{\text {rd }}$ generation bred on the farm. They were the result of systematic mating between wild and farmed broodstock (either males or females were wild broodstock) in each generation. This strategy aims to avoid inbreeding. In 4 sea cages of 600 abalone each, the heaviest 15 males and 15 females cage ${ }^{-1}$ were selected and the same number of abalone were randomly sampled from the sea cage for the randomly sampled broodstock. The wild broodstock consisted of 40 males and 40 females collected from coastal areas of northern Brittany by professional divers.

Abalone were kept in 151 conditioning buckets, with 4 to 8 abalone from the same treatment in a bucket, for approximately 5 mo. Maturity of the broodstock was checked during routine hatchery operations before the induction of reproduction. All abalone were regarded as suitable for reproduction. An average of $90 \%$ of males and females in each group spawned after induction using a temperature shock of $+4^{\circ} \mathrm{C}$ and UV-irradiated seawater. During spawning, females of each origin were grouped in one container while males were separated into individual containers. Within $2 \mathrm{~h}$ of spawning, pooled oocytes were subdivided according to the number of males having spawned and fertilized with the sperm of each male diluted to a target concentration of 10 spermatozoa $\mathrm{egg}^{-1}$. The success rates of fertilisation and hatching were estimated to be $80 \%$. Following $5 \mathrm{~d}$ of rearing through incubation, hatching and the various larval stages, 200000 larvae from each treatment were allowed to settle in each nursery tank $(1.4 \times 0.25 \times$ $0.6 \mathrm{~m})$ containing 120 plastic plates $(0.6 \times 0.3 \mathrm{~m})$ covered with Ulvella lens (Daume et al. 2004). In total, this spawning procedure was repeated 4 times between July and September 2014 (17, 21, 28 July and 15 September) with different farmed and wild abalone each time.

After 10 mo, when the juveniles reached approximately $10 \mathrm{~mm}$ in mean shell length, they were anes- thetized using $3.5 \%$ ethanol and the density was adjusted to 300 juveniles tank ${ }^{-1}$. A $5 \%$ mortality rate was observed during this procedure. In November 2015, at the age of 16 mo, juveniles were transferred into sea cage structures. Each sea cage contained 75 abalone: 25 abalone from wild parents, 25 abalone from parents selected based on weight and 25 abalone whose parents were randomly selected, each sea cage corresponding to a spawning period. There were 3 cages (technical replicates or blocks) for each spawning period ( $\mathrm{n}=12$ cages in total). Abalone from each treatment were individually marked with 2 coloured plastic tags $(2 \times 2 \mathrm{~mm})$ fixed with cyanoacrylate glue. Due to high mortality during the winter rearing period, only 13 juveniles from the randomly selected broodstock were added per cage for the third spawning. Following a winter storm, one replicate cage from the first spawning was lost.

The commercial rearing procedure of the France Haliotis farm was applied to the abalone in the cages: fresh algae was added to each cage once per month, allowing ad libitum access to food until May 2017. The algae provided were mainly composed of Palmaria palmata, Laminaria digitata and Saccharina latissima, depending on the season.

\subsection{Experimental procedure}

When the abalone were 34 mo old, the sea cages were brought back to the laboratory facilities at the farm. The cages were placed in a tank $(1 \times \mathrm{w} \times \mathrm{h}: 6 \times$ $1.4 \times 0.6 \mathrm{~m}$ ) next to the laboratory until further analysis. Abalone were out of the water for a maximum of $1 \mathrm{~h}$ during the transport from the sea cage concession area. Fresh, filtered seawater from the sea was then provided. Apart from the abalone used to record diurnal rhythm (see below), animals were left for $10 \mathrm{~d}$ in the tank before physiological and behavioural measurements were carried out. Special care was taken not to handle them in order to prevent any stress.

To evaluate the effect of domestication on behaviour and physiology, immune status measurements, righting, hiding and predator tests were performed. Diurnal rhythm was studied in aquaria after 1 mo of acclimation to the laboratory conditions. Growth and survival measurements were performed during the 3 yr rearing period. Abalone were tested only once and marked at the end of each test so that they were not used twice before they were replaced in the cage. 


\subsection{Behavioural measurements}

\subsubsection{Diurnal rhythm and feed intake}

To study the circadian rhythm, 33 glass aquaria $(\mathrm{w} \times \mathrm{l} \times \mathrm{h}: 20 \times 35 \times 20 \mathrm{~cm})$ were used containing $12 \mathrm{l}$ of seawater. In addition, 3 supplementary aquaria without abalone were used to control for algal degradation. The 2 extremities of these aquaria were devoted to shelter or feeding: shelter was provided in the form of a baked clay shelter $(\mathrm{w} \times 1 \times \mathrm{h}: 6 \times 20 \times$ $6 \mathrm{~cm})$, while a baked clay ring was used to hold the alga $P$. palmata in the feeding area. The quantity of algae was adjusted to ensure ad libitum feeding (at least $1 / 3$ of the initial quantity was remaining at the end of each period). Each tank received $20 \mathrm{l} \mathrm{h}^{-1}$ of $3 \mu \mathrm{m}$ mechanically filtered seawater at a temperature of $15 \pm 0.5^{\circ} \mathrm{C}$. The $14: 10 \mathrm{~h}$ photoperiod was adjusted to the seasonal rhythm (light: 06:30 to 20:30 h). To avoid stressful conditions during light changes, the light was adjusted slowly for 30 min during dawn (06:00 to $6: 30 \mathrm{~h}$ ) and dusk (20:30 to $21: 00 \mathrm{~h})$ using a dimmer (Gold Star, Besser Elektronik). Tanks were cleaned twice a week using a siphoning hose and the water filters were changed every day. All tanks were continuously videotaped using 3 digital cameras (TSWD6001HPSC, Sygonix) linked to a $24 \mathrm{~h}$ recording device (TVVR 40021, Abus). All behavioural analyses were performed using the Observer program (Observer ${ }^{\odot} \mathrm{XT}$, Noldus).

Just after transport from the sea, 3 abalone from each treatment were randomly sampled from each cage and placed in 11 aquaria (1 aquarium cage $^{-1}$, $\mathrm{n}=33$ abalone in total treatment ${ }^{-1}$ ). They were gently detached, measured and weighed. A phosphorescent tag was glued to the shell with cyanoacrylate gel to record their night-time behaviour. Previous observations have shown that the stress of detachment and tagging has almost no effect on immune status after $1 \mathrm{~d}$ (Hooper et al. 2011) and on diurnal rhythm after $8 \mathrm{~d}$ (data not shown). After 1 mo of acclimation, the diurnal rhythm was video-recorded over $48 \mathrm{~h}$, allowing measurements during both day and night. The videos were analysed at 16 times normal speed and slowed to 4 times when necessary. To avoid bias during video analysis, aquaria were not identified in terms of treatments. Individual behaviour was followed using the individual shell tags. The percentage of time spent hiding (under the baked clay hiding place), moving in the open zone, immobile in the open zone and eating the algae (less than $2 \mathrm{~cm}$ from the algae with small movements of the algae observed) were calculated for each aquarium by averaging the behaviour of the 3 individuals during the $2 \mathrm{~d}$ of observations.

Feed intake was measured during the 1 mo acclimation period. Fresh P. palmata was placed in the aquarium every 3-4 d. Fresh and remaining algae were dried with absorbent paper and weighed each time. The ingested quantity of algae was calculated in $\mathrm{g} \mathrm{g}^{-1}$ of wet abalone, taking into account changes in algal mass in the 3 supplementary aquaria.

\subsubsection{Predator, hiding and righting tests}

For the righting and hiding tests, glass aquaria $(\mathrm{w} \times$ $1 \times$ h: $20 \times 35 \times 20 \mathrm{~cm}$ ) filled with $5 \mathrm{l}$ of seawater were used, equipped with a baked clay shelter for the hiding test and nothing for the righting test. For the predator test a plastic tank $(1 \times \mathrm{w} \times \mathrm{h}$ : $0.4 \times 2.5 \times$ $0.15 \mathrm{~m}$ ) filled with $50 \mathrm{l}$ of seawater was used, with a $10 \times 10 \mathrm{~cm}$ square grid printed on the bottom and on the side of the tank. The aquaria and tanks were cleaned at least 3 times, and seawater at the same temperature as the rearing tank was replaced between the tests for each individual abalone in order to remove any alarm cues possibly associated with abalone mucus (Bancalà 2009). These tests were performed during the daytime.

For each test, an abalone was randomly selected from a cage, gently detached and immediately placed in the experimental aquarium or tank. For each test, $\mathrm{n}=1$ or 2 abalone per treatment and per sea cage were used ( $\mathrm{n}=19$ abalone minimum in total treatment $^{-1}$ ). Abalone were replaced in their cage only when all the abalone from the same cage had been tested to eliminate any effect of stress chemical cues on other tested individuals.

\subsubsection{Righting test}

Individual abalone were placed on their back in the centre of the aquarium. The time to right themselves was measured from the time the abalone were placed in the aquarium until they had fully turned over. The number of attempts to turn over (defined as the number of times the abalone placed its foot on the bottom and contracted its muscle) was also recorded.

\subsubsection{Hiding test}

An individual abalone was placed on its foot at one side of the aquarium. The time it took to make its first 
movement, the time for it to reach the hiding place and the time before it was completely hidden were recorded, with a maximum time of $15 \mathrm{~min}$ if an abalone did not move into the shelter.

\subsubsection{Predator test}

An abalone was placed in the centre of the $150 \mathrm{l}$ tank. When the abalone had a semi-relaxed or relaxed foot attached to the bottom of the tank, usually between 30 and $60 \mathrm{~s}$ afterwards, a starfish (Marthasterias glacialis, $20 \mathrm{~cm}$ width) was held in contact with the abalone's foot for $10 \mathrm{~s}$. While the starfish touched the abalone, any protective swivelling movement of the abalone shell was recorded as well as any mucus release, any turn-around behaviour and any movement directly away from the starfish. The number of abalone that performed these 4 escape behaviours was recorded. The time until the first movement was measured. In addition, after the abalone began escaping, the time spent moving, the number of squares crossed and the number of mucus releases were recorded during the $5 \mathrm{~min}$ period of the test. The M. glacialis were collected on the outside of abalone sea cages, placed in a $30 \mathrm{l}$ aquarium and fed with dead, non-experimental abalone twice $\mathrm{wk}^{-1}$ during the $2 \mathrm{wk}$ experimental period. The starfish were released in the area where they were collected at the end of the experiment.

\subsection{Immune function measurements after stress}

The immune status of abalone, especially after a farm stress event such as grading, which involves shaking (Lachambre et al. 2017a), can be evaluated using the density of haemocytes in circulation as well as their phagocytosis activity (Hooper et al. 2011). Abalone were subjected to stress by 20 min of shaking in air with an oyster farm spat screener (3 jolts $\mathrm{s}^{-1}$ of $3 \mathrm{~cm}$ height) and a further $40 \mathrm{~min}$ of exposure to air. This procedure is a common stressor experienced by abalone during the screening process on abalone farms. Phagocytosis efficiency and total haemocyte count (THC) were measured $1 \mathrm{~h}$ after the beginning of the stress period. A total of 2 abalone treatment ${ }^{-1}$ and cage $^{-1}$ were used $\left(n=22\right.$ in total treatment ${ }^{-1}$ ). Haemolymph was collected from the pedal sinus in less than $1 \mathrm{~min}$, by an experienced experimenter using a refrigerated $2 \mathrm{ml}$ syringe and $25 \mathrm{G} \times 5 / 8$ needles. The haemolymph was transferred into a vial on ice. Samples were treated just after collection to avoid aggregation. To measure phagocytosis efficiency, a protocol adapted from Travers et al. (2008) was followed using 2 replicates of $25 \mu \mathrm{l}$ of haemolymph. Procedures described in Lachambre et al. (2017b) were applied with the following modifications: analyses were performed on a FACSVerse flow cytometer (Becton Dickinson) equipped with 3 lasers (405, 488 and $640 \mathrm{~nm}$ ), a universal loader and a flow sensor to estimate the sample volume analysed. The immunological parameters were calculated using BD FACSuite software v.1.0.6. Phagocytosis efficiency was defined as the percentage of haemocytes that had engulfed 3 or more beads. The number of beads engulfed per active cell was also calculated. For the THC samples, 2 replicates of $25 \mu$ of haemolymph were immediately added to $3.4 \%$ formalin (175 $\mu \mathrm{l})$ in a 96 well plate and kept at $4{ }^{\circ} \mathrm{C}$ before analysis. The fluid was diluted and incubated for $30 \mathrm{~min}$ in dark conditions with SYBR green fluorescent dye (4 $\mu \mathrm{l}$, Molecular Probes; $10^{-3}$ dilution of the commercial stock solution) before flow cytometry. Results were

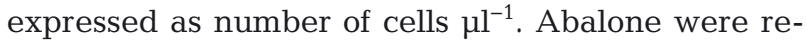
turned to the commercial sea cages on the farm after sampling.

\subsection{Growth, survival and reproduction}

\subsubsection{Size and weight at 10 and 16 months}

Maximum shell length was measured to the nearest mm using Vernier callipers and weights were recorded to the nearest $0.01 \mathrm{~g}$ at 10 mo for 75 abalone $\operatorname{tank}^{-1}$ ( $\mathrm{n}=300$ abalone treatment ${ }^{-1}$ ). The measured abalone were removed from the experiment in order to avoid any stress effect on growth. This procedure was performed again at 16 mo of age when transferring the animals into the sea cage $(n=264 \mathrm{~min}$. treatment $^{-1}, \mathrm{n}=864$ in total).

\subsubsection{Size, weight and survival at 34 mo of age}

Survival at sea was obtained from the numbers of remaining live abalone in each treatment at 34 mo versus their numbers at 16 mo of age. Length and total weight of all these abalone were measured at 34 mo of age ( $\mathrm{n}=63$ abalone min. treatment $^{-1}, \mathrm{n}=$ 231 in total). Randomly sampled abalone were dissected in June 2017, corresponding to the period of reproduction for the species in this area $(\mathrm{n}=$ at least 3 abalone treatment ${ }^{-1}$ and cage $^{-1}, \mathrm{n}=$ minimum 42 abalone treatment ${ }^{-1}, \mathrm{n}=148$ in total). The weights 
of the muscle tissue (comprising the epipodium, the foot muscle and the adductor muscle), gonad (in the conical organ and part of the spire, separating it from the digestive gland with a scalpel), digestive system (comprising the stomach and crop but not the oesophagus and intestine) and shell were recorded. Indices were calculated by expressing these weights as a percentage of the wet body weight.

\subsection{Shell colour and pattern}

Shell colour and pattern of a sample of the abalone at $34 \mathrm{mo}$ ( $\mathrm{n}=148$ in total) were assessed visually by a trained experimenter (Fig. 1). The lighter colour of the juvenile part of the shell was not included in this assessment. Shell colour was classified into 2 categories (Liu et al. 2009): a green shade category comprising shells ranging from dark brown to green, and an orange category comprising shells with an orange to red colour. There were 3 categories of shell pattern: homogenous colour, a discolouration in one part of the shell (less than $1 / 3$ of the shell) and stripes on at least $1 / 3$ of the surface of the shell (Fig. 1).

\subsection{Statistical analysis}

The behavioural, physiological, survival and growth variables measured at 3 yr of age were analysed by a linear mixed effects analysis using the 'lmerTest' package (Bates et al. 2012) in $R$ and using the methodology described by Winter (2013). Differences of least squares means and the Satterthwaite's approximation to df were calculated using the 'difflsmeans' function. The model included the factors treatment (wild, selected or randomly selected) and spawning (1 to 4 ) as fixed effects and cage (1 to 11) as a random factor. For the growth data in the nursery, the model included the treatment (wild, selected or randomly selected) and spawning (1 to 4) as fixed effects, and tank (1 to 12) as a random factor. Because the spawning effect was never significant, it is not presented in the results. Because the df were not indicated in the $\mathrm{R}$ mixed model analysis, these were calculated as follows: $\mathrm{df}_{\text {numerator }}=k-1$, with $k$ being the number of different treatment groups $(k=$ 3 for origins) plus $1 \mathrm{df}$ for the random factor (cages/ tanks), $\mathrm{df}_{\text {denominator }}=n-k$ with $n$ as the total $\mathrm{df}$ of the data and $k$ the total of the df of the fixed and random effects (for example, for data at $3 \mathrm{yr}$ of age: 11 cages $-1,3$ origins -1 , and 4 spawning periods $-1 ; k=15)$.

When assumptions of homogeneity of variance and normal distribution of the residuals were not verified, a $\log (x+1)$, inverse $(x)$, or square root transformation was used before carrying out the analysis. If the normal distribution of the residuals was not satisfied by the transformed data but the variance was homogenous, a Kruskal-Wallis test was performed. If the homogeneity of variance was not verified, a Welch test was performed, as recommended by Day \& Quinn (1989). If a treatment effect was observed, a Mann-Whitney test was performed for post hoc analysis. A chi-squared test was used for the analysis of frequency data. All data are presented as least square means (lsmean) $\pm \mathrm{SE}$, unless otherwise stated.

\section{RESULTS}

\subsection{Behavioural traits}

\subsubsection{Circadian and feed intake}

No significant effects of broodstock origin on diurnal rhythm during the night and day periods were observed (Table 1), nor for the quantity of algae ingested per gram of abalone during the 1 mo of the experiment $\left(F_{3,14}=1.48, \mathrm{p}=0.251\right)$ (Table 1$)$.
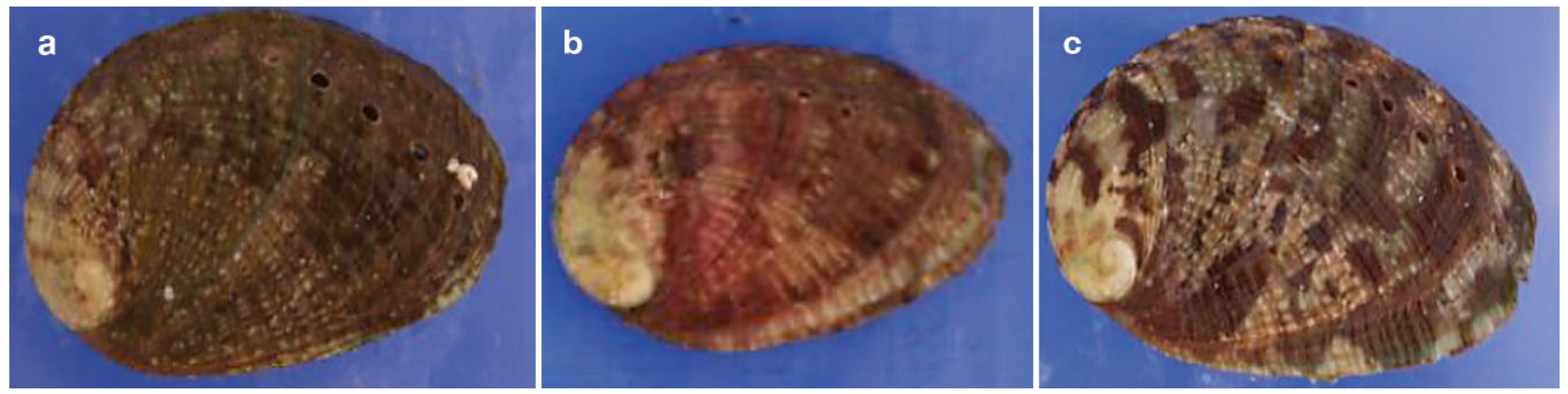

Fig. 1. Shell patterns of abalone with (A) homogenous colour, (B) discolouration in one part of the shell and (C) stripes on at least one-third of the shell 
Table 1. Diurnal rhythm of abalone Haliotis tuberculata offspring from 3 different broodstock origins (wild, farmed selected on weight and farmed randomly sampled) observed over $48 \mathrm{~h}$ and feed intake observed over $1 \mathrm{mo}^{\mathrm{n}} \mathrm{n}=11$ aquaria treatment $^{-1}$ with 3 abalone in each, mixed model unless otherwise stated. Results are least square means \pm SE

\begin{tabular}{|c|c|c|c|c|c|}
\hline \multirow[t]{2}{*}{ Behaviour } & \multirow[t]{2}{*}{ Wild } & \multirow[t]{2}{*}{ Selected } & \multirow{2}{*}{$\begin{array}{l}\text { Randomly } \\
\text { sampled }\end{array}$} & \multicolumn{2}{|c|}{ Origin effect } \\
\hline & & & & $F / H$ & $\mathrm{p}$ \\
\hline \multicolumn{6}{|l|}{ Day period } \\
\hline Time hiding $(\%)^{\Upsilon}$ & $99.9 \pm 2.09$ & $96.3 \pm 1.94$ & $99.7 \pm 2.09$ & 0.68 & 0.522 \\
\hline Time immobile in open zone $(\%)^{\curlyvee}$ & $0.3 \pm 2.04$ & $3.2 \pm 1.89$ & $0.03 \pm 2.04$ & 0.61 & 0.557 \\
\hline \multicolumn{6}{|l|}{ Night period } \\
\hline Time hiding (\%) & $56.1 \pm 6.46$ & $48.3 \pm 6.02$ & $54.4 \pm 6.46$ & 0.53 & 0.600 \\
\hline Time immobile in open zone $(\%)^{\delta}$ & $6.7 \pm 2.36$ & $6.9 \pm 2.19$ & $4.3 \pm 2.36$ & 1.05 & 0.592 \\
\hline Time eating $(\%)^{\alpha}$ & $18.1 \pm 3.43$ & $21.1 \pm 3.19$ & $19.8 \pm 3.43$ & 0.26 & 0.773 \\
\hline Time moving $(\%)$ & $18.9 \pm 2.92$ & $23.6 \pm 2.72$ & $21.6 \pm 2.92$ & 0.94 & 0.411 \\
\hline \multicolumn{6}{|l|}{ Feed intake during 4 wk } \\
\hline $\begin{array}{l}\text { Quantity of algae ingested per gram of abalone } \\
\text { (g wet algae } \mathrm{g}^{-1} \text { abalone } \mathrm{mo}^{-1} \text { ) }\end{array}$ & $0.67 \pm 0.064$ & $0.80 \pm 0.067$ & $0.80 \pm 0.064$ & 1.48 & 0.251 \\
\hline \multicolumn{6}{|c|}{${ }{ }_{\text {Welch test }}{ }^{\delta}{ } \mathrm{Kruskal}_{\text {-Wallis test }}{ }^{\alpha}{ }$ square root transformation } \\
\hline
\end{tabular}

\subsubsection{Righting test}

No significant differences in mean righting time $\left(F_{3,47}=2.28, \mathrm{p}=0.113\right)$, nor in the number of attempts to turn over $\left(F_{2,4.2}=1.17, \mathrm{p}=0.395\right)$, between wild, weight-selected and randomly sampled progenies were observed (Table 2).

\subsubsection{Hiding test}

An effect of broodstock origin was observed for the time until first movement $\left(F_{3,42}=4.02, \mathrm{p}=0.024\right)$ and the time to reach the hiding place $(H=6.53, \mathrm{df}=2$, $\mathrm{p}=0.038)$ but not for the time until abalone were fully hidden $(H=4.04, \mathrm{df}=2, \mathrm{p}=0.132)$. The offspring of selected parents took longer before the first movement $(t=2.58, \mathrm{p}=0.010)$ and longer to reach the hiding place compared to the offspring of wild parents $\left(Q_{\mathrm{obs}}=318, \mathrm{p}=0.014\right)$. The mean times were intermediate for the offspring of randomly sampled broodstock (Table 2).

\subsubsection{Predator test}

No effects of broodstock origin were observed for the time until first movement $\left(F_{2,17.7}=0.56, \mathrm{p}=0.583\right)$,

Table 2. Responses during behavioural tests of abalone Haliotis tuberculata offspring from 3 different broodstock origins (wild, farmed selected on weight and farmed randomly sampled); $\mathrm{n}=19$ abalone minimum treatment ${ }^{-1}$, mixed model unless otherwise stated. Results are least square means \pm SE. Values with different superscripts are significantly different $(p<0.05)$

\begin{tabular}{|c|c|c|c|c|c|}
\hline \multirow[t]{2}{*}{ Behaviour } & \multirow[t]{2}{*}{ Wild } & \multirow[t]{2}{*}{ Selected } & \multirow{2}{*}{$\begin{array}{l}\text { Randomly } \\
\text { sampled }\end{array}$} & \multicolumn{2}{|c|}{ Origin effect } \\
\hline & & & & $F / H / \chi^{2}$ & $\mathrm{p}$ \\
\hline \multicolumn{6}{|l|}{ Righting test } \\
\hline Righting time $(\mathrm{s})^{\alpha}$ & $63.3 \pm 6.79$ & $54.4 \pm 6.66$ & $42.8 \pm 7.13$ & 2.28 & 0.113 \\
\hline Number of attempts to turn over $\gamma$ & $2.4 \pm 0.46$ & $1.6 \pm 0.44$ & $1.2 \pm 0.48$ & 1.17 & 0.395 \\
\hline \multicolumn{6}{|l|}{ Hiding test } \\
\hline Time until the first movement $(\mathrm{s})^{\alpha}$ & $30^{\mathrm{a}} \pm 5.0$ & $48^{\mathrm{b}} \pm 5.0$ & $39^{\mathrm{ab}} \pm 6.1$ & 4.02 & 0.024 \\
\hline Time to reach the hiding place $(\mathrm{s})^{\delta}$ & $60^{\mathrm{a}} \pm 28.3$ & $132^{\mathrm{b}} \pm 28.5$ & $79^{\mathrm{ab}} \pm 35.0$ & 6.53 & 0.038 \\
\hline Time before complete hiding $(\mathrm{s})^{\delta}$ & $242 \pm 58.6$ & $231 \pm 59.2$ & $94 \pm 72.4$ & 4.04 & 0.132 \\
\hline \multicolumn{6}{|l|}{ Predator test } \\
\hline $\begin{array}{l}\text { Number of abalone that performed } \\
\text { the } 4 \text { escape behaviours } \chi\end{array}$ & 12 out of $21^{a}$ & 5 out of $21^{b}$ & 6 out of $18^{\mathrm{ab}}$ & 5.20 & 0.074 \\
\hline Time spent moving (s) & $198 \pm 12.2$ & $193 \pm 12.3$ & $194 \pm 13.3$ & 0.04 & 0.959 \\
\hline Number of squares crossed & $12.6 \pm 0.98$ & $12.0 \pm 0.99$ & $12.5 \pm 1.07$ & 0.10 & 0.901 \\
\hline Number of mucus releases & $2.2^{\mathrm{a}} \pm 0.26$ & $1.5^{\mathrm{b}} \pm 0.26$ & $1.4^{b} \pm 0.28$ & 4.10 & 0.023 \\
\hline Time until the first movement $(\mathrm{s})^{\curlyvee}$ & $11.8 \pm 2.29$ & $14.3 \pm 2.31$ & $14.9 \pm 2.50$ & 0.56 & 0.583 \\
\hline
\end{tabular}


Table 3. Immunity parameters after shaking and air exposure stress in abalone Haliotis tuberculata offspring from 3 different broodstock origins (wild, farmed selected on weight and farmed randomly sampled); $\mathrm{n}=16$ abalone minimum treatment $^{-1}$, mixed model unless otherwise stated. Results are least square means $\pm \mathrm{SE}$

\begin{tabular}{|c|c|c|c|c|c|}
\hline \multirow[t]{2}{*}{ Parameter } & \multirow[t]{2}{*}{ Wild } & \multirow[t]{2}{*}{ Selected } & \multirow{2}{*}{$\begin{array}{l}\text { Randomly } \\
\text { sampled }\end{array}$} & \multicolumn{2}{|c|}{ Origin effect } \\
\hline & & & & $F / H$ & $\mathrm{P}$ \\
\hline Phagocytosis efficiency (\%) & $13.3 \pm 1.15$ & $14.2 \pm 1.21$ & $14.3 \pm 1.56$ & 0.18 & 0.832 \\
\hline Number of beads engulfed cell-1${ }^{-1}$ & $5.3 \pm 0.16$ & $5.2 \pm 0.15$ & $5.3 \pm 0.18$ & 0.25 & 0.777 \\
\hline Total haemocyte count (cells $\mu \mathrm{l}^{-1}$ ) & $3396 \pm 800.6$ & $3611 \pm 886.0$ & $1861 \pm 1152.9$ & 0.93 & 0.399 \\
\hline$\Upsilon_{\text {Welch test }}$ & & & & & \\
\hline
\end{tabular}

the time spent moving $\left(F_{3,45}=0.04, \mathrm{p}=0.959\right)$ or the number of squares crossed $\left(F_{3,45}=0.10, \mathrm{p}=0.901\right)$. However, a significant effect of treatment group was observed for the number of mucus releases $\left(F_{3,45}=\right.$ 4.10, $\mathrm{p}=0.023$ ): wild offspring released mucus more often compared to the offspring of selected parents $(t=-2.43, \mathrm{p}=0.020)$ and the offspring of randomly sampled ones $(t=-2.50, \mathrm{p}=0.020)$. In addition, there was a trend between treatments in the numbers of abalone that performed the 4 escape behaviours $\left(\chi^{2}=\right.$ 5.20, df $=2, \mathrm{p}=0.074)$ : more offspring of wild broodstock origin performed the complete behavioural antipredation sequences compared to offspring of selected parents $\left(\chi^{2}=4.84, \mathrm{df}=1, \mathrm{p}=0.028\right)$, while offspring of randomly sampled broodstock were intermediate but not significantly different (Table 2).

\subsection{Immune function}

No significant effects of broodstock origin were found for phagocytosis efficiency $\left(F_{3,52}=0.18, \mathrm{p}=\right.$ 0.832), number of beads engulfed per active cell (Welch test, $F_{2,29.7}=0.25, \mathrm{p}=0.777$ ) or total haemocyte count $\left(F_{3,27}=0.93, \mathrm{p}=0.399\right)$ (Table 3$)$.

\subsection{Growth and survival}

At 10 and $16 \mathrm{mo}$, no significant effects of broodstock origin were observed for length $\left(F_{3,884}=3.24\right.$, $\mathrm{p}=0.108$ at $10 \mathrm{mo} ; F_{3,848}=0.01, \mathrm{p}=0.997$ at $16 \mathrm{mo}$ ) and weight (Welch test, $F_{2,2.7}=1.85, \mathrm{p}=0.311$ at $10 \mathrm{mo} ; F_{3,848}=0.08, \mathrm{p}=0.991$ at $16 \mathrm{mo}$ ) (Fig. 2).

No significant effects of broodstock origin were observed for length $\left(F_{3,216}=0.04, \mathrm{p}=0.958\right)$ and weight $\left(F_{3,216}=0.10, \mathrm{p}=0.903\right)$ at 34 mo of age. In addition, no significant difference in survival rate was observed during the sea-rearing period $\left(F_{3,18}=\right.$ 0.92, $\mathrm{p}=0.412$ ) (Table 4). For the dissection data, no significant effects of broodstock origin were observed for the muscle, gonad or shell indices (re- spectively, $F_{3,133}=0.45, \mathrm{p}=0.636 ;$ Welch test, $F_{2,35.1}=$ $\left.1.00, \mathrm{p}=0.379 ; F_{3,130}=1.81, \mathrm{p}=0.167\right)$. There was, however a significant effect for the digestive system index $\left(F_{3,133}=6.00, \mathrm{p}=0.003\right)$ : offspring of wild abalone had a higher digestive system index than offspring from selected parents $(t=-3.26, \mathrm{p}=0.001)$ and offspring of randomly selected broodstock $(t=-2.80$, $\mathrm{p}=0.006$ ) (Table 4).
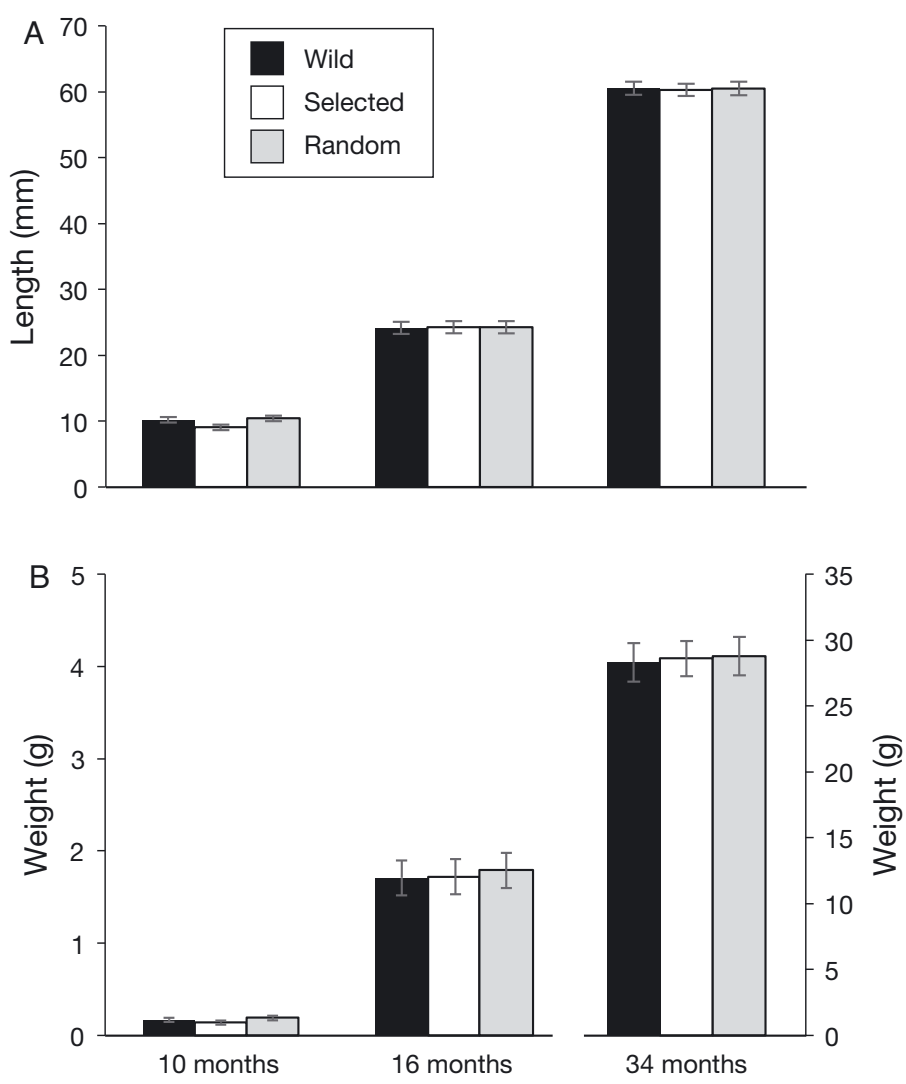

Fig. 2. (A) Length and (B) weight of abalone Haliotis tuberculata offspring at 10, 16 and 34 months of age from 3 different broodstock origins (wild, farmed selected for weight and farmed randomly sampled); $\mathrm{n}=300$ abalone treatment $^{-1}$ at $10 \mathrm{mo}, \mathrm{n}=264$ abalone minimum treatment ${ }^{-1}$ at $16 \mathrm{mo}, \mathrm{n}=63$ minimum treatment ${ }^{-1}$ for length and weight at $34 \mathrm{mo}$. Mixed model unless otherwise stated (least square means $\pm \mathrm{SE}$ ). Note different scale for weight at $34 \mathrm{mo}$ 
Table 4. Survival and dissection measures at 34 mo of age of abalone Haliotis tuberculata offspring from 3 different broodstock

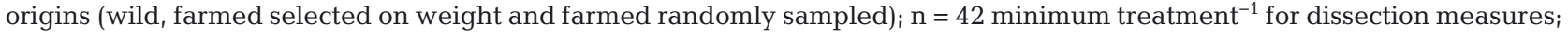
mixed model unless otherwise stated. Values with different superscripts are significantly different $(p<0.05)$

\begin{tabular}{|c|c|c|c|c|c|}
\hline \multirow[t]{2}{*}{ Parameter } & \multirow[t]{2}{*}{ Wild } & \multirow[t]{2}{*}{ Selected } & \multirow{2}{*}{$\begin{array}{l}\text { Randomly } \\
\text { sampled }\end{array}$} & \multicolumn{2}{|c|}{ Origin effect } \\
\hline & & & & $F$ & $\mathrm{p}$ \\
\hline Survival rate (\%) & $80.7 \pm 4.62$ & $83.6 \pm 4.62$ & $75.0 \pm 4.62$ & 0.92 & 0.412 \\
\hline Muscle index $(\%)^{\beta}$ & $35.0 \pm 0.34$ & $39.9 \pm 0.30$ & $34.6 \pm 0.37$ & 0.45 & 0.636 \\
\hline Gonad index $(\%)^{r}$ & $9.5 \pm 0.45$ & $9.5 \pm 0.40$ & $9.5 \pm 0.48$ & 1.00 & 0.379 \\
\hline Digestive system index $(\%)^{\alpha}$ & $6.2 \pm 0.19^{\mathrm{a}}$ & $5.3 \pm 0.17^{b}$ & $5.4 \pm 0.20^{\mathrm{b}}$ & 6.00 & 0.003 \\
\hline Shell index $(\%)^{\beta}$ & $25.6 \pm 0.47$ & $26.4 \pm 0.42$ & $26.4 \pm 0.49$ & 1.81 & 0.167 \\
\hline
\end{tabular}

\subsection{Shell colour and pattern}

Broodstock origin effects were found for shell pattern $\left(\chi^{2}=11.0, \mathrm{df}=2, \mathrm{p}=0.027\right)$, and shell colour $\left(\chi^{2}=\right.$ $6.0, \mathrm{df}=2, \mathrm{p}=0.049$ ) (Fig. 3). Offspring from wild parents had less stripes compared to offspring from
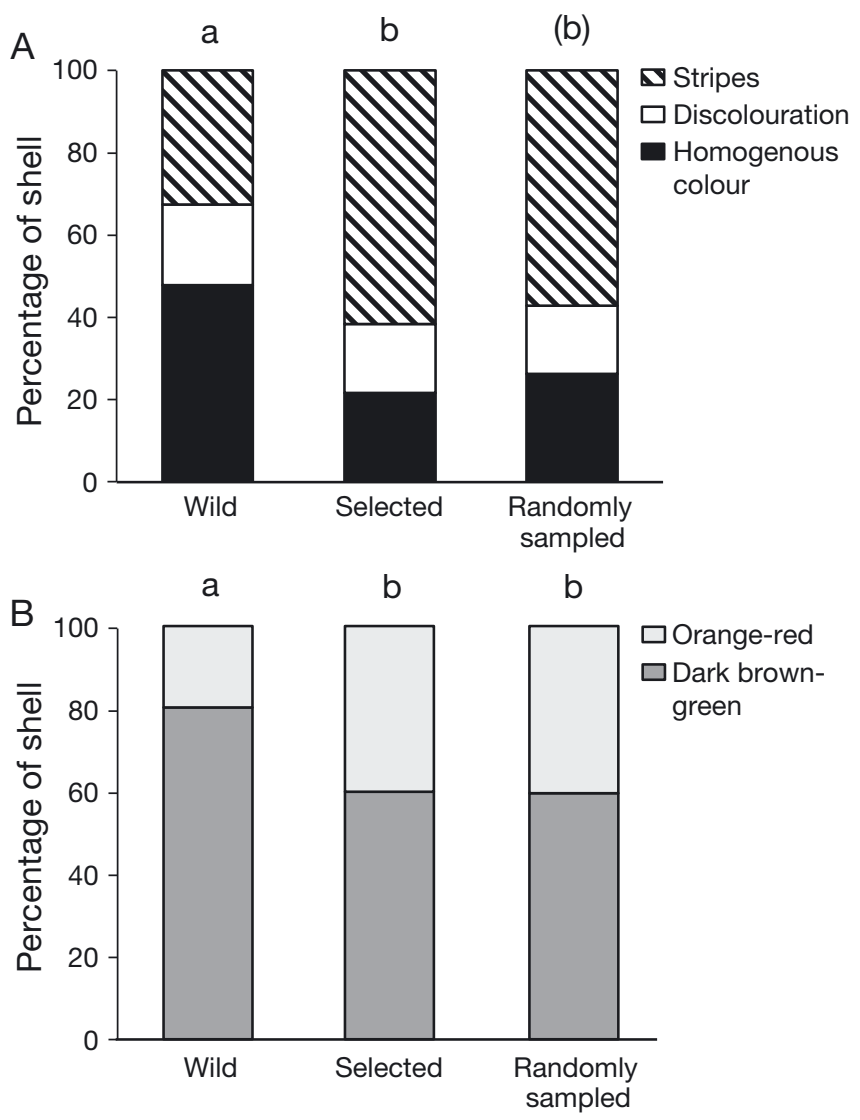

Fig. 3. (A) Shell pattern and (B) shell colour of offspring from 3 different abalone Haliotis tuberculata broodstock origins (wild, farmed selected on weight and farmed randomly sampled) ( $\mathrm{n}=42$ abalone minimum treatment ${ }^{-1}, \mathrm{n}=148$ in total, Pearson's chi-squared test). Values with different letters 'a' and ' $b$ ' differ $(p<0.05)$. Values with letters within parenthesis (b) tend to differ from values with letters ' $a$ ' $(p<0.10)$ broodstock selected based on weight $\left(\chi^{2}=10.0, \mathrm{df}=\right.$ $1, p=0.007)$ and tended to have less stripes than offspring of randomly sampled parents $\left(\chi^{2}=5.8, \mathrm{df}=1\right.$, $\mathrm{p}=0.054$ ) (respectively, 32.6 vs. 61.6 vs. $57.1 \%$ of the shells with stripes). For shell colour, more offspring from wild origin parents had a brown-green shell colour compared to those from broodstock selected based on weight $\left(\chi^{2}=5.1, \mathrm{df}=1, \mathrm{p}=0.024\right)$ and from randomly selected broodstock $\left(\chi^{2}=4.6, \mathrm{df}=1, \mathrm{p}=\right.$ 0.032 ) (respectively, 80.4 vs. 60.0 vs. $59.5 \%$ of the shells with dark brown-green colour).

\section{DISCUSSION}

The aim of our experiment was to study the early consequences of the domestication process, and of genetic selection to improve growth, on behavioural and physiological traits in different progenies. The broodstocks for the 3 sets of offspring were probably not very different genetically, as the farm broodstock were derived from crosses between farmed and wild parents, and only one round of selection on weight had been imposed in the case of the offspring of selected broodstock. Thus, it was not surprising that no significant effect was observed on the selected trait (growth) and most of the physiological and diurnal rhythm traits. Surprisingly however, the offspring from the selected broodstock showed an alteration in hiding behaviour and responses to a predator, both in quantitative terms and also in the qualitative nature of the responses.

Abalone from broodstock selected for on weight and randomly sampled broodstock also emitted mucus less frequently on contact with a predator compared to abalone from wild broodstock. In addition, fewer offspring from parents selected for weight completed the full escape behaviour repertoire, showing a reduction in terms of effective escape behaviour compared to abalone from wild parents. The sequences 
of these escape behaviour subunits are stereotyped and depend on the predator type (Bullock 1953). If the subunits of the escape response to starfish are expressed in the wrong order or context, they appear to be less efficient (Parsons \& Macmillan 1979). Ejected mucus is thought to interfere with the starfish's olfactory system, to obscure the abalone's escape direction (Day et al. 1995, Bancalà 2009). Several hypotheses might explain the lower frequency of mucus release, perhaps due to a reduction in the production of mucus glands or to an increased stimulation threshold required to trigger mucus releases in offspring of selected broodstock compared to offspring of wild origin.

Most Haliotis spp. are photophobic species (Momma \& Sato 1969, 1970, Shepherd 1973). This strong photonegative behaviour is likely a way to avoid predators, and was observed in our experiment, with abalone spending at least $96 \%$ of their time hiding during the daytime. When exposed to an illuminated place during the hiding test, abalone from selected broodstock and randomly sampled broodstock took longer to make the first movement and to reach the hiding place compared to offspring from wild abalone. Several hypotheses can explain this result. Abalone perceive light via their retinas (Tasaki \& Tsukahara 1971). A longer latency before moving could result from a structural change in the photoreceptive cells of the retina (Kataoka \& Yamamoto 1981). However, these effects of selection have not been reported in other domesticated animals. Another hypothesis could be a lower energy level in offspring from the weight-selected broodstock compared to offspring from wild abalone. Two other results from the experiment allow us to refute this hypothesis: abalone from weight-selected parents ingested the same quantity of algae per gram of abalone as those in other treatments during the 1 mo diurnal rhythm measurements, and no differences were observed during the righting test, which is a good indirect indicator of metabolic and energetic status (Baldwin et al. 2007) as well as of subsequent abalone survival (Lachambre et al. 2017b). The third hypothesis, and probably the most plausible, is a change in the stimulus threshold required to trigger a response to a dangerous situation (i.e. being exposed in the light to predator). When abalone were placed in situations with no stress response involved, no significant differences of behaviour were observed: there were no detectable feeding differences between the 3 progeny groups, nor any diurnal rhythm differences. Although faster feeding was reported in domesticated salmonids compared to fish collected in the wild (Yamamoto \& Reinhardt 2003), no change of diurnal rhythm has been reported in the literature as a direct effect of domestication.

More offspring from weight-selected broodstock and randomly selected ones had an orange-coloured and striped shell compared to offspring from wild broodstock, which had a more homogenous, browngreenish colour. Abalone shell colour is known to be affected by their diet (Marchais et al. 2017). However, in our case, for most of the rearing period the abalone received a monospecific type of algae, depending on the season. Consequently, no feeding choice was possible in the cages. The colour differentiation observed probably had a genetic origin, as demonstrated in many other molluscan species (Williams 2017). Studies on H. discus hannai highlighted a genetic control of colour and reported a new variant with orange shell colouration, distinguishable from the wild green-shelled abalone (Liu et al. 2009), and a novel orange variant was reported for $H$. diversicolor (Xin et al. 2017). In our experiment, even though the relaxed selection that accompanies the transition from field to captive environments might explain some of the variation with an absence of selection on the farmed parental generation that might produce the more orange, striped offspring, another hypothesis should be considered. Abalone were selected for weight but an unintentional selection for shells with a brighter colour and nicer looking pattern cannot be excluded. Personal preferences often influence the selection of breeding stock, and these biases may be very subtle and are often unintentional (Price 1999). In addition, the fact that shell colour is one of the most highly heritable traits (Lachambre 2017) supports the rapid changes of colour observed between generations. However, this modification of shell colour and pattern would probably impair the camouflage and predator avoidance advantages of the wild colour and pattern, which highlights how important it is to control possible unintentional selection if animals are produced for ranching or a stock enhancement program (Hansen \& Gosselin 2013).

We expected a response in the targeted trait to the selection of the $5 \%$ heaviest individuals in the broodstock. However, no weight or size gains were observed at 10, 16 and 34 months in the progeny of weight-selected parents. Numerous studies have shown that growth is a heritable trait in Haliotis spp. (Lucas et al. 2006, Robinson et al. 2013, Roussel et al. 2013, Camara \& Symonds 2014, Brokordt et al. 2015), although the estimation of heritability varies widely among species and for the same species. Neverthe- 
less, improved growth of the $F_{1}$ generation is not always observed in spite of the fact that growth in weight is a heritable trait. A reduced or lack of a selective effect on growth rate in the $F_{1}$ generation has often been reported in selected species, with selection responses being identified only after 2 generations of domestication (Falconer \& Mackay 1996). Phenotypic variability is the physical expression of what a particular gene or set of genes (the genotype) will produce under particular environmental conditions (Elliott 2000). The $5 \%$ heaviest individuals in the broodstock might be heavier due to environmental heterogeneity but not as a result of a higher genetic potential. In addition, the survival of early juvenile abalone and the quality of the algae and diatoms used for juvenile feeding are difficult to control, especially after larval settlement, and every procedure during this period may induce high mortality (Daume et al. 2004, de Viçose et al. 2012). However, temperature, light exposure, handling and predation were similar between the treatments, as well as the food quality at settlement and the density and food quality after the age of $10 \mathrm{mo}$. It is difficult to maintain stable environment conditions during the first months of culture in the nursery, due to the interactions between settlement, Ulvella lens growth and the effects of juvenile density at 4-5 mo of age. The variability of density and food during the first $10 \mathrm{mo}$ of development may have compromised the expression of the genetic potential for growth in the offspring of weight-selected broodstock. The smaller digestive system observed in the progeny of the selected broodstock at the adult stage may partly confirm this hypothesis, and may indicate food deprivation during early development.

No differences between the progeny groups were observed in survival rate or immune status following stress. Because immune and stress responses are essential for survival, selection pressure probably does not lead to rapid modification of genes associated with these functions (Nesse \& Young 2000), which might explain the lack of a difference after one generation in abalone.

According to Price (1999), domestication is based on 3 processes. First, there is an intensified selection of traits preferred by humans. Second, the transition from the wild to a captive environment can be expected to be accompanied by relaxed natural selection such as predation and starvation. The third domestication process described by Price (1999) is inadvertent selection under captivity, which can lead to adaptation. Recently, epigenetic mechanisms have been highlighted corresponding to the control of gene expression during development on physiology and metabolism (Symonds et al. 2009) as well as on behaviour regulation (Lester et al. 2011, Jensen 2015). During our experiment, this maternal effect was controlled, because broodstock were conditioned in a similar way for approximately 4-5 mo, with similar food, temperature and light control, and a minimum of handling. However, because a difference in stress response has been shown in wild compared to farmed abalone (Lachambre et al. 2017a,b), the impact of stress during the conditioning process cannot be completely excluded.

Inadvertent selection under captivity can lead to adaptation of captive animals to farm conditions. Farm-rearing conditions such as high stocking density (Travers et al. 2010) and handling during grading practices (Hooper et al. 2011) imply that even the progeny from wild parents, studied at 3 yr of age, had already been subjected to inadvertent selection. The selection processes during captive rearing probably explain an important part of the differences observed between farmed abalone and wild $H$. tuberculata, where abalone from the farm showed a reduced retraction in reaction to finger contact and quicker immune recovery after a stress compared to wild abalone (Lachambre et al. 2017a) and spent less time moving at night than wild abalone (Lachambre et al. $2017 b$ ). In contrast to the experiments described above, the progeny in our experiment were bred in the same environment and were reared under common conditions. Thus, inadvertent selection and behavioural acclimation were similar. The effects observed for the progeny from the randomly selected broodstock may result from inadvertent selection of the broodstock, but further studies are needed to evaluate this.

Recent selection of marine animals is based mainly on growth or meat yield (Lorenzen et al. 2012). Behaviour and other traits such as physiology and growth are probably polygenic and would show a quantitative inheritance pattern (Jensen 2006), even for molluscs. For example, a significant heritability $\left(h^{2}=0.2-0.8\right)$ has been shown for antipredator behaviour in squid (Sinn et al. 2006) and scallops $\left(h^{2}=\right.$ 0.36-0.57) (Brokordt et al. 2012). Foraging behaviour heritability had less additive genetic value and greater residual $\left(h^{2}=0.05-0.08\right)$ in squid. In abalone, heritability of distance travelled after a stress event has also been shown to have a significant but a very weak heritability $\left(h^{2}=0.05\right)$ (Robinson et al. 2013). Our results are consistent with the general trend observed during domestication, but are surprising in terms of the rapidity of behavioural modification. 


\section{CONCLUSIONS}

Domestication is a complex process with several mechanisms implicated in the transition from wild to farmed animals. Marine animals that produce very large numbers of offspring and may have phenotypic plasticity to allow for different environments encountered by settling larvae may show many rapid changes. It is difficult to untangle the effect of the environment from that of genetics. By controlling the environment during parental conditioning and by placing the offspring in a similar environment, the genetic effects of domestication were studied here. The different progenies compared in our study were at different early stages of domestication (Teletchea \& Fontaine 2014). The offspring from wild broodstock spent their entire life cycle in captivity, where natural selection was absent (relaxed selection), and inadvertent selection due to the farm environment was probably significant. This group probably represents the first step of the domestication process. The offspring from randomly sampled farmed broodstock (resulting from crosses between wild and farmed broodstock) showed some differences from the offspring of the wild broodstock in terms of shell pattern and colour, probably resulting from unintentional selection. There also appear to be small differences in terms of response to a predator, showing that these traits may be changed in less than 2 generations in a farming context. For the offspring from weightselected farm broodstock, no responses to selection were observed for offspring length and weight, but modifications of the responses to a predator, of hiding behaviour and of shell colour and pattern were observed, either in quantity or in quality. Overall, these results indicate that conscious selection can modify the behaviour and shell colour of abalone undergoing a domestication process in only one generation, even though many other phenotypic traits studied in the 3 offspring groups were similar. These rapid modifications represent a real challenge if the offspring from selected broodstock or even randomly sampled broodstock are to be used in ranching or enhancement of abalone fisheries. In addition, such changes would be expected to become more pronounced following more generations of conscious or unintentional selection in a farm. The degree of domestication of farm animals is likely to affect their fitness in the context of ranching or population enhancement operations. Abalone are one of the few marine taxa where ranching or marine stock enhancement is reported to be economically profitable (Kitada 2018). However, even if recapture rates are relatively high, a large variation in recapture rates has been reported (Kitada 2018). Considering their better performance in anti-predator behaviour sequences, the use of wild broodstocks for marine stock enhancement programs should be encouraged.

Acknowledgements. The authors thank the team of France Haliotis: Xavier Lesage, Frederic Laurans, Mickael Gleeson, Iain McKensy and Maryvonne Leroux for the provision and care of the animals and assistance during the experiment. This experiment was conducted at the France Haliotis abalone farm. Animals and some parts of the setup were supplied by the farm. Two persons employed by France Haliotis were involved in this experiment: Sylvain Huchette, PhD, manager of the farm, and Sébastien Lachambre, a PhD student partially funded by France Haliotis and ANRT (CIFRE No. 2014 0643). This work benefited from the support of the European Union (FEAMP) via the program 42 of the FEAMP 'innovation in aquaculture' through the 'GenOrmeau' project.

\section{LITERATURE CITED}

Baldwin J, Elias JP, Wells RMG, Donovan DA (2007) Energy metabolism in the tropical abalone, Haliotis asinina Linne: comparisons with temperate abalone species. J Exp Mar Biol Ecol 342:213-225

* Bancalà F (2009) Function of mucus secretion by lamellose ormer, Haliotis tuberculata lamellosa, in response to starfish predation. Anim Behav 78:1189-1194

Bates DM, Maechler M, Bolker B (2012) Lme4: linear mixedeffects models using S4 classes. https://cran.r-project. org/web/packages/lme4/lme4.pdf

Brokordt K, Farias W, Lhorente JP, Winkler F (2012) Heritability and genetic correlations of escape behaviours in juvenile scallop Argopecten purpuratus. Anim Behav 84:479-484

* Brokordt KB, Winkler FM, Farías WJ, González RC, Castaño F, Fullsack P, Herbinger CM (2015) Changes of heritability and genetic correlations in production traits over time in red abalone (Haliotis rufescens) under culture. Aquacult Res 46:2248-2259

*Bullock RH (1953) Predator recognition and escape responses of some intertidal gastropods in presence of starfish. Behaviour 5:130-140

* Camara MD, Symonds JE (2014) Genetic improvement of New Zealand aquaculture species: programmes, progress and prospects. NZ J Mar Freshw Res 48:466-491

Clavier J, Chardy P (1989) Investigation into the ecology of the ormer (Haliotis tuberculata L.), factors influencing spatial distribution. Aquat Living Resour 2:191-197

Conover DO (1998) Local adaptation in marine fishes: evidence and implications for stock enhancement. Bull Mar Sci 62:477-493

Cox KW (1962) Review of the abalone of California. Fish Bull 188:1-133

* Daume S, Huchette S, Ryan S, Day RW (2004) Nursery culture of Haliotis rubra: the effect of cultured algae and larval density on settlement and juvenile production. Aquaculture 236:221-239

* Day RW, Quinn GP (1989) Comparisons of treatments after an analysis of variance in ecology. Ecol Monogr 59: 433-463 
Day R, Dowell A, Sant G, Klemke J, Shaw C (1995) Patchy predation: foraging behaviour of Coscinasterias calamaria and escape responses of Haliotis rubra. Mar Freshwat Behav Physiol 26:11-33

de Viçose GC, Viera MP, Huchette S, Izquierdo MS (2012) Improving nursery performances of Haliotis tuberculata coccinea: nutritional value of four species of benthic diatoms and green macroalgae germlings. Aquaculture 334-337:124-131

Douxfils J, Mandiki SNM, Marotte G, Wang N and others (2011) Does domestication process affect stress response in juvenile Eurasian perch Perca fluviatilis? Comp Biochem Physiol A 159:92-99

Elliott NG (2000) Genetic improvement programmes in abalone: What is the future? Aquacult Res 31:51-59

Falconer DS, Mackay TFC (1996) Introduction to quantitative genetics, $4^{\text {th }}$ edn. Longman, London

Geiger DL (2000) Distribution and biogeography of the Haliotidae (Gastropoda: Vetigastropoda) world-wide. Boll Malacol 35:57-120

Griffiths AM, Gosselin LA (2008) Ontogenetic shift in susceptibility to predators in juvenile northern abalone, Haliotis kamtschatkana. J Exp Mar Biol Ecol 360:85-93

Hansen SC, Gosselin LA (2013) Do predators, handling stress or field acclimation periods influence the survivorship of hatchery-reared abalone Haliotis kamtschatkana outplanted into natural habitats? Aquat Conserv 23:246-253

Hines AH, Pearse JS (1982) Abalones, shells, and sea otters: dynamics of prey populations in Central California. Ecology 63:1547-1560

Hooper C, Day R, Slocombe R, Benkendorff K, Handlinger J (2011) Effect of movement stress on immune function in farmed Australian abalone (hybrid Haliotis laevigata and Haliotis rubra). Aquaculture 315:348-354

Huntingford F, Adams C (2005) Behavioural syndromes in farmed fish: implications for production and welfare. Behaviour 142:1207-1221

Jensen P (2006) Domestication - from behaviour to genes and back again. Appl Anim Behav Sci 97:3-15

Jensen P (2015) Adding 'epi-' to behaviour genetics: implications for animal domestication. J Exp Biol 218:32-40

Kataoka S, Yamamoto TY (1981) Diurnal changes in the fine-structure of photoreceptors in an abalone, Norditis discus. Cell Tissue Res 218:181-189

Kitada S (2018) Economic, ecological and genetic impacts of marine stock enhancement and sea ranching: a systematic review. Fish Fish 19:511-532

Kunzl C, Sachser N (1999) The behavioral endocrinology of domestication: a comparison between the domestic guinea pig (Cavia aperea f. porcellus) and its wild ancestor, the cavy (Cavia aperea). Horm Behav 35:28-37

Lachambre S (2017) Mise en place d'un plan de sélection génétique pour l'ormeau européen Haliotis tuberculata. $\mathrm{PhD}$ dissertation, Université Bretagne Occidentale, Brest

Lachambre S, Day R, Boudry P, Huchette S, Rio-Cabello A, Fustec T, Roussel S (2017a) Stress response of farmed European abalone reveals rapid domestication process in absence of intentional selection. Appl Anim Behav Sci 196:13-21

Lachambre S, Huchette S, Day R, Boudry P, Rio-Cabello A, Fustec T, Roussel S (2017b) Relationships between growth, survival, physiology and behaviour-a multicriteria approach to Haliotis tuberculata phenotypic traits. Aquaculture 467:190-197
Lester BM, Tronick E, Nestler E, Abel T and others (2011) Behavioral epigenetics. Ann N Y Acad Sci 1226:14-33

Liu X, Wu FC, Zhao HG, Zhang GF, Guo XM (2009) A novel shell color variant of the pacific abalone Haliotis discus hannai Ino subject to genetic control and dietary influence. J Shellfish Res 28:419-424

* Lorenzen K, Beveridge MCM, Mangel M (2012) Cultured fish: integrative biology and management of domestication and interactions with wild fish. Biol Rev Camb Philos Soc 87:639-660

Kucas T, Macbeth M, Degnan SM, Knibb W, Degnan BM (2006) Heritability estimates for growth in the tropical abalone Haliotis asinina using microsatellites to assign parentage. Aquaculture 259:146-152

Marchais V, Jolivet A, Herve S, Roussel S and others (2017) New tool to elucidate the diet of the ormer Haliotis tuberculata (L.): digital shell color analysis. Mar Biol 164:71

Momma H, Sato R (1969) The locomotion behavior of the disc abalone, Haliotis discus hannai Ino, and the Siebold's abalone, Haliotis sieboldi Reeve, in the fishing grounds. Tohoku J Agr Res 20:150-157

Momma H, Sato R (1970) The locomotion behavior of the disc abalone, Haliotis discus hannai Ino, in a tank. Tohoku J Agr Res 21:20-25

Nesse RM, Young EA (2000) Evolutionary origins and functions of the stress response. In: Fink G (ed) Encyclopedia of stress, Vol 2. Academic Press, San Diego, CA, p 79-84 * Parsons DW, Macmillan DL (1979) Escape response of abalone (Mollusca, Prosobranchia, Haliotidae) to predatory gastropods. Mar Behav Physiol 6:65-82

Poore GCB (1972) Ecology of New Zealand abalones, Haliotis species (Mollusca: Gastropoda). 2. Seasonal and diurnal movements. N Z J Mar Freshw Res 6:246-258

* Price EO (1984) Behavioural aspects of animal domestication. Q Rev Biol 59:1-32

Price EO (1999) Behavioral development in animals undergoing domestication. Appl Anim Behav Sci 65:245-271

Rauw W, Kanis E, Noordhuizen-Stassen E, Grommers FJ (1998) Undesirable side effects of selection for high production efficiency in farm animals: a review. Livest Prod Sci 56:15-33

Rhode C, Hepple JA, Jansen S, Davis T, Vervalle J, Bestervan der Merwe AE, Roodt-Wilding R (2012) A population genetic analysis of abalone domestication events in South Africa: implications for the management of the abalone resource. Aquaculture 356-357:235-242

Robinson N, Li XX, Hayes B (2010) Testing options for the commercialization of abalone selective breeding using bioeconomic simulation modelling. Aquacult Res 41: e268-e288

Kobinson N, Smith B, Cooke I, Strugnell J (2013) A snail's pace: a preliminary analysis of the effects of stress and genetics on movement of Haliotis. Aquaculture 376-379: 25-35

Koussel V, Charreyron J, Labarre S, Van Wormhoudt ASH (2013) First steps on technological and genetic improvement of European abalone (Haliotis tuberculata) based on investigations in full-sib families. Open J Genet 3:224-233

Shepherd SA (1973) Studies on southern Australian abalone (genus Haliotis). I. Ecology of five sympatric species. Aust J Mar Freshwater Res 24:217-257

Sinn DL, Apiolaza LA, Moltschaniwskyj NA (2006) Heritability and fitness-related consequences of squid personality traits. J Evol Biol 19:1437-1447

Symonds ME, Sebert SP, Hyatt MA, Budge H (2009) Nutri- 
tional programming of the metabolic syndrome. Nat Rev Endocrinol 5:604-610

Tasaki K, Tsukahara Y (1971) Receptor potential and spike activity in molluscan retina. Vision Res 11:1194

Teletchea F, Fontaine P (2014) Levels of domestication in fish: implications for the sustainable future of aquaculture. Fish Fish 15:181-195

Thorpe JE (2004) Life history responses of fishes to culture. J Fish Biol 65:263-285

Travers MA, Le Goïc N, Huchette S, Koken M, Paillard C (2008) Summer immune depression associated with increased susceptibility of the European abalone, Haliotis tuberculata to Vibrio harveyi infection. Fish Shellfish Immunol 25:800-808

Travers MA, Meistertzheim AL, Cardinaud M, Friedman

Editorial responsibility: Ian Fleming,

St. John's, Newfoundland and Labrador, Canada
CS, Huchette S, Moraga D, Paillard C (2010) Gene expression patterns of abalone, Haliotis tuberculata, during successive infections by the pathogen Vibrio harveyi. J Invertebr Pathol 105:289-297

Williams ST (2017) Molluscan shell colour. Biol Rev Camb Philos Soc 92:1039-1058

Winter B (2013) Linear models and linear mixed effects models in R with linguistic applications. arXiv:1308.5499

* Xin Z, Feilong F, Weiwei Y, Xuan L, Caihuan K (2017) Identification of a microsatellite marker that is completely linked to shell colour in small abalone, Haliotis diversicolor. Aquacult Res 48:3894-3900

Yamamoto T, Reinhardt UG (2003) Dominance and predator avoidance in domesticated and wild masu salmon Oncorhynchus masou. Fish Sci 69:88-94

Submitted: March 28, 2018; Accepted: January 29, 2019

Proofs received from author(s): March 25, 2019 